$\xi=$ 离

\title{
What factors influence the utilisation of all doses of vaccines with subsequent doses for under-five children in Ghana?
}

\author{
Mustapha Immurana ${ }^{1 *}$, Arabi, U. ${ }^{2}$ \\ ${ }^{1}$ Research Scholar, Department of Economics, Mangalore University, Mangalagangotri - 574119, Karnataka State, India \\ ${ }^{2}$ Professor and Research Guide, Department of Economics, Mangalore University, Mangalagangotri - 574119, Karnataka State, India \\ *Corresponding author E-mail: mustaphaimmurana@gmail.com
}

\begin{abstract}
Pneumonia, Diarrhoea, Measles, Polio and Whooping Cough are major killers of children in the world. However, one of the most effective ways of preventing these diseases is through utilising completely their respective vaccines which are normally administered in doses. Therefore given that the 2014 Ghana Demographic and Health Survey (GDHS) report showed a fall in the coverage of the subsequent doses of the Pentavalent, Pneumococcal, Polio and Rotavirus vaccines for children in Ghana, this study investigated the factors that influence the Utilisation of all Doses of these vaccines as well as the Measles vaccine. Using Data from the 2014 GDHS and employing the binary probit model, the study among other findings revealed that, children from the Eastern, Northern and Western regions were found to be less probable to have received all the doses of the Polio and Pentavalent vaccines. Also unemployed mothers were found to be less likely to demand for all the doses of the Measles, Pentavalent, Pneumococcal and Rotavirus vaccines for their children. Moreover, rising age of the household head was associated with falling utilization of all the doses of the Pneumococcal, Pentavalent and Polio vaccines for children. Furthermore, children with single mothers were found to be less likely to have received all doses of both the Polio and Pentavalent vaccines. Also uneducated mothers were found to be less likely to demand for all the doses of the Polio, Pentavalent and Measles vaccines for their children relative to mothers with secondary education. In addition mothers without health insurance were found to be less likely to utilize all the doses of the Measles and Polio vaccines for their children. Therefore reinvigoration of regional centeredness of child health utilization drives, aiding single, unemployed and uneducated women as well as strengthening the free maternal health insurance registration scheme, could be effective tools in ensuring full utilisation of all doses of these vaccines.
\end{abstract}

Keywords: Child Health Utilization; Ghana; Immunization.

\section{Introduction}

Under -five Mortality continues to remain a major concern among various countries across the globe; hence it is not surprising that the sustainable development goal (SDG) 3.2 has the target of reducing under-five mortalities to at least 25 per thousand live births.

According to the World Health Organisation (WHO), in 2015 alone, 5.9 million children under -five died, mostly due to preventable causes such as pneumonia, diarrhoea, and malaria (WHO, 2016a). Further among the causes of under-five mortality, Polio is a viral disease which normally affects children and can paralyse the entire body in hours by affecting the nervous system (WHO, 2014). In addition, Whooping cough is also regarded as a major cause of infant mortality (Loving, 2016), which in 2008 according to the WHO (as cited in Loving, 2016) killed about 195 thousand children. Also, measles is recognised as one of the main causes of mortalities in young children (WHO, 2016b).

However, all these major killers of children: pneumonia, diarrhoea, polio, measles and whooping cough can be prevented using the pneumococcal, rotavirus, polio, measles and pentavalent vaccines respectively.

According to the Expanded Immunization Programme in Ghana, children are supposed to take three doses each of the pneumococcal and pentavalent vaccines, four doses of the polio vaccine (if polio 0 which is given at birth is added), two doses of the rotavirus vaccine and two doses of the measles vaccine. However, the 2014 Ghana Demographic and Health Survey (GDHS) indicates a fall in the coverage of the subsequent or successive doses of the polio, pentavalent, pneumococcal and rotavirus vaccines for children in Ghana (Ghana Statistical Service [GSS], Ghana Health Service [GHS] \& ICF International, 2015) even though children need to take all these doses in order to be fully protected from these diseases.

Therefore given that under-five mortality rate in Ghana is estimated to be 60 deaths per thousand live births (GSS, GHS \& ICF International, 2015) with a recent report indicating that diarrhoea and pneumonia have been significant causes of under-five mortality during the period 2012-2013 in Ghana (GHS, n.d.), this study investigated the factors that influence the utilisation of all doses of vaccines with subsequent doses for under five children in Ghana. Thus the study brought to light the factors affecting the full utilisation of all doses of the polio, pentavalent, pneumococcal and rotavirus vaccines for children in Ghana. This would help in tackling the falling up-take of the subsequent doses of the pneumococcal and rotavirus vaccines which could be the reason for the rising amount of under-five deaths in Ghana attributable to pneumonia and diarrhoea recently. Also it would help in tackling the factors that affect the up-take of the subsequent doses of the polio vaccine which is a great threat to the polio free status of Ghana that has been achieved since 2008 according to the GHS (2015). Thus In all, it helped in revealing the factors that influence the up-take of all the doses of vaccines with subsequent doses individually and 
hence would help in achieving the SDG 3.2 target of at least 25 deaths per thousand live births by 2030 .

\section{Review of literature}

On the theoretical literature, since there is a derived demand for health and individuals are the producers of health according to Grossman (1999), these vaccines (all their doses) would be utilised for children in order to produce better health. Thus, the vaccines become inputs in the health production function. Therefore the production of better health using these vaccines would enhance the performance of children when they grow, in both the market and non-market sectors.

On the empirical Literature, In Nigeria Cockcroft et al. (2014) found among other factors that mother's education was linked with the likelihood that a child received measles vaccination. Russo et al. (2015) found younger mother's age, child being the $3^{\text {rc }}$ born or beyond and poor parental attitude as some of the factors influencing incomplete immunization among children in Cameroon. Further, older maternal and child's age and lower distance from the immunization centre among others were found to be strongly linked with the likelihood of increased influenza vaccination up take for children in Kenya (Otieno et al., 2014). Also belonging in the rich index by mother was found by Lakew et al (2015) to be one of the determinants of full immunization of children in Ethiopia.

On Ghana, it has been found that children membership of National Health Insurance Scheme (NHIS), mother's education and geographical location determined full immunization of children (Dwumoh et al. (2014). Also antenatal care was found to increase the odds of immunization among children (McGlynn, 2012). In addition, similar studies have been done by Bosu et al. (1997), Matthews and Diamond (1997) and Duah-Owusu (n.d.)

Moreover, Immurana and Arabi (2016a) among other findings revealed that, mother's marital status influenced the utilisation of all the successive doses of the rotavirus and pneumococcal vaccines for children in Ghana. Further, mother's employment was found to influence the utilisation of the initial and successive doses of the rotavirus and pneumococcal vaccine. Immurana and Arabi (2016b) among other results revealed that, non-wealthy households, mothers without health insurance and uneducated mothers were less probable to demand the $2^{\text {nd }}$ dose of the measles vaccine for their children in Ghana. Further, Immurana and Arabi (2016c) also found employed mothers to be more probable to utilise all the successive doses of both the polio and pentavalent vaccines for their children.

Among all the works on Ghana above, apart from Immurana and Arabi (2016a, b \& c), none of them investigated the factors that affect the uptake of individual vaccines. However, this work is novel because it did not look at the determinants of demand for each dose of a particular vaccine but rather investigated the factors that influence the utilisation of all doses of a particular vaccine (as a single regression equation). Thus if all doses of a vaccine have been utilised for a child or not rather than if a specific dose has been utilised for a child or not as done by Immurana and Arabi (2016a, b \& c).

Thus since the main motive is to ensure that all children utilise all the doses of each vaccine, finding out the factors that affect the utilisation of all doses of a vaccine using a single regression equation could be a better approach.

\section{Data and methods}

This paper used data from a cross-sectional survey (2014 GDHS) undertaken in early September to mid-December, 2014 by the GSS, GHS and other partners. During the survey, data were captured concerning the immunisation status of children as well other socio-economic, maternal, child and household characteristics.
Thus on immunisation, if all the doses of a particular vaccine has been given to a child, this study treated it as 1 and if otherwise 0 . Thus concerning the three doses each of the pneumococcal and pentavalent vaccines, four doses of the polio vaccine, two doses of the rotavirus vaccine and two doses of the measles vaccine, it means we have Five (5) separate regressions, each representing the utilisation of all doses of a vaccine.

Since children are too young to make decisions for themselves, it is assumed that these vaccines would be utilised for them based on the mothers expected utility. Thus if a mother's expected utility for utilising all the doses of a vaccine is greater than not utilising, then all the doses would be utilised for the child and if a mother's expected utility for utilising all the doses of a vaccine is less than not utilising, then all the doses would not be utilised for the child. Therefore given that the various dependent variables (utilisation of all doses of each vaccine) were binary or dichotomous, the study adopted the binary probit regression model. Also since Williams (2012) posits that marginal effects help in given more intuitive understanding to results from non-liner models such as the probit model, we reported the results using the average marginal effects (AMEs). We therefore used a simplified model of estimation as

$$
\mathrm{Dv}=\not y \mathrm{E}+\Omega \mathrm{F}+\mathrm{bG}+\mu
$$

Where Dv is the dependent variable, which shows the likelihood that a mother would utilise all the doses of a vaccine for the child or not. E is mother's and partner's features such as age, education, employment e.t.c, $\mathrm{F}$ represents characteristics of the child such as sex, birth order and age, whiles $\mathrm{G}$ indicates the remaining socioeconomic characteristics such as region, household wealth status, ethnicity, residence type, e.t.c., with $\varkappa$, $\Omega$, and $\mathrm{h}$ being vector of parameters of the explanatory variables and $\mu$ representing the error term. In this study all categorical explanatory variables were treated as dummy variables. Further, wealth status, mother's marital status and religion were recoded from how they appeared in the original data to their current state in this study.

\section{Results and discussion}

\subsection{Descriptive statistics with Pearson chi square}

This section as shown in Tables 1 and 2 revealed how the utilisation of all doses of the respective vaccines were distributed among the various categorical independent variables. Also, the Pearson chi square was employed to show the strength of association between various categorical independent variables and the utilisation of all doses of the respective vaccines. From Table 1, it can be seen that there were statistically significant relationships between utilisation of all doses of the Pentavalent, Measles and Pneumococcal vaccines and region, religion, ethnicity, mother's education, money to seek medical care by mother, and partner's education. Also there were statistically significant relationships between utilisation of all doses of the Measles and Pneumococcal vaccines, and residence and household wealth status. Further, the results also showed statistically significant relationships between utilisation of all doses of the Pentavalent and Measles vaccines and mother's employment.

Also in Table 2, the results showed that there were statistically significant relationships between utilisation of all doses of the Rotavirus and Polio vaccines and region, residence, religion, ethnicity, mother's education, mother's health insurance, money and distance to seek medical care by mother, partner's education, sex of household head and household wealth status. Further, descriptive statistics on variables can also be seen in Tables 1 and 2. Given that, the Person chi square only shows the association between utilisation of all doses of each vaccine and individual categorical independent variables without controlling for other factors that may affect the utilisation of all doses of each vaccine, this study went a step further to employ a multivariate probit model by including other variables. 
Table 1: Descriptive Statistics with Pearson Chi Square Analyses on Utilisation of All Doses of Pentavalent, Measles and Pneumococcal Vaccines

\begin{tabular}{|c|c|c|c|c|c|c|c|c|c|}
\hline \multirow[t]{2}{*}{ Variable } & \multicolumn{2}{|c|}{$\begin{array}{l}\text { Pentavalent } \\
(\%)\end{array}$} & \multirow[t]{2}{*}{ Chi-square } & \multicolumn{2}{|c|}{ Measles (\%) } & \multirow[t]{2}{*}{ Chi-square } & \multicolumn{2}{|c|}{$\begin{array}{l}\text { Pneumococcal } \\
(\%)\end{array}$} & \multirow[t]{2}{*}{ Chi-square } \\
\hline & No & Yes & & No & Yes & & No & Yes & \\
\hline Region & & & $129.2249 * * *$ & & & $65.5539 * * *$ & & & $188.0073^{* * *}$ \\
\hline Western & 29.86 & 70.14 & & 57.14 & 42.86 & & 54.81 & 45.19 & \\
\hline Central & 18.74 & 81.26 & & 62.24 & 37.76 & & 53.20 & 46.80 & \\
\hline Greater Accra & 20.85 & 79.15 & & 59.78 & 40.22 & & 38.13 & 61.87 & \\
\hline Volta & 22.96 & 77.04 & & 58.06 & 41.94 & & 48.12 & 51.88 & \\
\hline Eastern & 25.93 & 74.07 & & 53.80 & 46.20 & & 46.78 & 53.22 & \\
\hline Brong Ahafo & 15.61 & 84.39 & & 56.21 & 43.79 & & 31.78 & 68.22 & \\
\hline Northern & 34.09 & 65.91 & & 71.34 & 28.66 & & 62.65 & 37.35 & \\
\hline Upper East & 17.26 & 82.74 & & 58.72 & 41.28 & & 46.05 & 53.95 & \\
\hline Upper West & 15.82 & 84.18 & & 63.85 & 36.15 & & 56.20 & 43.80 & \\
\hline Residence & & & 0.9529 & & & $4.5172 * *$ & & & $20.3739 * * *$ \\
\hline Urban & 22.05 & 77.95 & & 62.78 & 37.22 & & 46.21 & 53.79 & \\
\hline Rural & 23.17 & 76.83 & & 59.94 & 40.06 & & 52.42 & 47.58 & \\
\hline Religion & & & $20.5658 * * *$ & & & $16.6899 * * *$ & & & $13.9908 * * *$ \\
\hline Islam & 20.81 & 79.19 & & 64.04 & 35.96 & & 49.82 & 50.18 & \\
\hline Traditional/Spiritualist/No religion & 30.82 & 69.18 & & 67.43 & 32.57 & & 58.07 & 41.93 & \\
\hline Ethnicity & & & $114.2734 * * *$ & & & $44.1331 * * *$ & & & $79.9677 * * *$ \\
\hline Akan & 22.64 & 77.36 & & 58.49 & 41.51 & & 48.94 & 51.06 & \\
\hline Ga/Dangme & 20.16 & 79.84 & & 56.45 & 43.55 & & 42.51 & 57.49 & \\
\hline Ewe & 21.30 & 78.70 & & 59.38 & 40.62 & & 45.48 & 54.52 & \\
\hline Guan & 21.88 & 78.13 & & 60.94 & 39.06 & & 42.74 & 57.26 & \\
\hline Mole-Dagbani & 19.28 & 80.72 & & 62.89 & 37.11 & & 49.97 & 50.03 & \\
\hline Grusi & 16.24 & 83.76 & & 56.36 & 43.64 & & 45.89 & 54.11 & \\
\hline Gurma & 39.02 & 60.98 & & 72.51 & 27.49 & & 66.85 & 33.15 & \\
\hline Mande & 7.14 & 92.86 & & 62.35 & 37.65 & & 41.18 & 58.82 & \\
\hline Other & 28.57 & 71.43 & & 58.10 & 41.90 & & 50.48 & 49.52 & \\
\hline Mother's Education & & & $14.7840 * * *$ & & & $22.0538 * * *$ & & & $46.4330 * * *$ \\
\hline Uneducated & 25.12 & 74.88 & & 65.05 & 34.95 & & 55.45 & 44.55 & \\
\hline Primary & 23.81 & 76.19 & & 60.47 & 39.53 & & 50.88 & 49.12 & \\
\hline Secondary & 20.40 & 79.60 & & 58.58 & 41.42 & & 45.73 & 54.27 & \\
\hline Higher & 20.28 & 79.72 & & 55.19 & 44.81 & & 40.87 & 59.13 & \\
\hline Insured & 22.14 & 77.86 & & 60.71 & 39.29 & & 48.48 & 51.52 & \\
\hline Marital Status & & & $33.3296 * * *$ & & & 0.3063 & & & 2.3480 \\
\hline Single & 27.30 & 72.70 & & 61.58 & 38.42 & & 51.41 & 48.59 & \\
\hline Married & 20.43 & 79.57 & & 60.81 & 39.19 & & 49.22 & 50.78 & \\
\hline Mother's Employment & & & $35.5548 * * *$ & & & $22.9819 * * *$ & & & 0.0132 \\
\hline Unemployed & 29.26 & 70.74 & & 67.21 & 32.79 & & 50.09 & 49.91 & \\
\hline Employed & 21.01 & 78.99 & & 59.49 & 40.51 & & 49.90 & 50.10 & \\
\hline $\begin{array}{l}\text { Permission to seek medical care/help by } \\
\text { mother }\end{array}$ & & & $4.8612^{* *}$ & & & 0.5920 & & & 0.0087 \\
\hline Big Problem & 27.35 & 72.65 & & 62.93 & 37.07 & & 49.73 & 50.27 & \\
\hline Not a Big Problem & 22.39 & 77.61 & & 60.93 & 39.07 & & 49.98 & 50.02 & \\
\hline Money to seek medical care/help by mother & & & $7.6875^{* * *}$ & & & $7.7867 * * *$ & & & $18.5770 * * *$ \\
\hline Big Problem & 24.33 & 75.67 & & 62.95 & 37.05 & & 52.97 & 47.03 & \\
\hline Not a Big Problem & 21.22 & 78.78 & & 59.30 & 40.70 & & 47.16 & 52.84 & \\
\hline Distance to seek medical care/help by mother & & & $9.1481 * * *$ & & & 2.6779 & & & $3.3605^{*}$ \\
\hline Big Problem & 25.23 & 74.77 & & 62.63 & 37.37 & & 51.78 & 48.22 & \\
\hline Not a Big Problem & 21.57 & 78.43 & & 60.34 & 39.66 & & 49.13 & 50.87 & \\
\hline Partner's Education & & & $16.4362 * * *$ & & & $11.8858 * * *$ & & & $64.3402 * * *$ \\
\hline Uneducated & 25.38 & 74.62 & & 64.18 & 35.82 & & 57.85 & 42.15 & \\
\hline Primary & 21.21 & 78.79 & & 58.95 & 41.05 & & 50.16 & 49.84 & \\
\hline Secondary & 20.19 & 79.81 & & 59.77 & 40.23 & & 46.77 & 53.23 & \\
\hline Higher & 20.04 & 79.96 & & 57.33 & 42.67 & & 40.70 & 59.30 & \\
\hline Sex of Household Head & & & 0.7029 & & & $3.2847 *$ & & & 1.0295 \\
\hline Male & 22.46 & 77.54 & & 61.72 & 38.28 & & 50.33 & 49.67 & \\
\hline Female & 23.57 & 76.43 & & 58.92 & 41.08 & & 48.71 & 51.29 & \\
\hline Sex of Child & & & 0.1592 & & & 0.0719 & & & 0.5532 \\
\hline Male & 22.94 & 77.06 & & 61.24 & 38.76 & & 50.44 & 49.56 & \\
\hline Female & 22.49 & 77.51 & & 60.89 & 39.11 & & 49.43 & 50.57 & \\
\hline Wealth Status & & & 0.5212 & & & $3.8210 *$ & & & $22.6691 * * *$ \\
\hline Non-Rich & 22.97 & 77.03 & & 61.85 & 38.15 & & 51.92 & 48.08 & \\
\hline Rich & 22.06 & 77.94 & & 58.99 & 41.01 & & 44.73 & 55.27 & \\
\hline
\end{tabular}


Table 2: Descriptive Statistics with Pearson Chi Square Analyses on Utilisation of All Doses of Rotavirus and Polio Vaccines

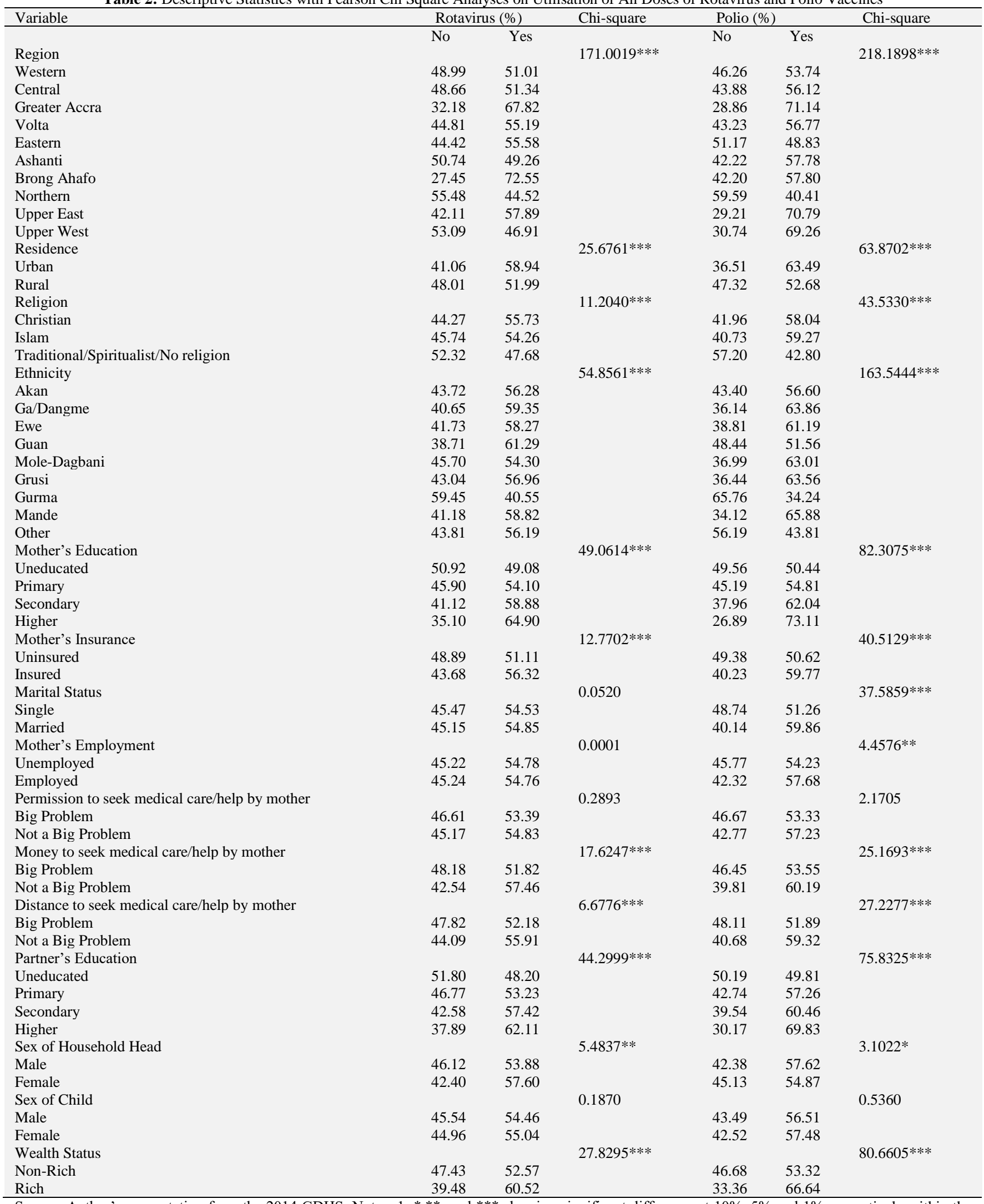

Source: Author's computation from the 2014 GDHS. Notes: $1 . * * *$, and *** showing significant difference at $10 \%, 5 \%$ and $1 \%$ respectively within the predictors and utilisation of all doses of Rotavirus and Polio vaccines among children in Ghana. 2. Traditional in this study means traditional/ spiritualist/ no religion. 


\section{Regression results}

Table 3: Probit Regressions on Determinants of Full Utilisation of Vaccines with Subsequent Dose (S)

\begin{tabular}{|c|c|c|c|c|c|}
\hline Dependent Variable & Pentavalent & Polio & Measles & Rotavirus & Pneumococcal \\
\hline Independent Variable & AME & AME & AME & AME & AME \\
\hline \multicolumn{6}{|l|}{ Region(Ref: Upper West) } \\
\hline Western & $-.1107938 * * *$ & $-.1603083 * * *$ & $.0619564 *$ & .0447919 & .0339517 \\
\hline Central & .003308 & $-.1344341 * * *$ & .0338538 & .053704 & .05755 \\
\hline Greater Accra & -.0539132 & $-.0732413^{*}$ & .0572557 & $.2016023 * * *$ & $.1734253 * * *$ \\
\hline Volta & -.0574622 & $-.1534051^{* * *}$ & $.1072518 * * *$ & $.0963826^{* *}$ & $.1030397 * *$ \\
\hline Eastern & $-.0810036 * *$ & $-.2244345^{* * * *}$ & $.1212638 * * *$ & $.1052747 * * *$ & $.112036^{* * *}$ \\
\hline Ashanti & -.0241715 & $-.1535217 * * *$ & .0164905 & .0247428 & .0127424 \\
\hline Northern & $-.1154858 * * *$ & $-.2080313 * * *$ & -.0086175 & .0310371 & -.0007991 \\
\hline Upper East & -.0347185 & .0053446 & $.0580195 * *$ & $.1098284 * * *$ & $.0914145 * * *$ \\
\hline \multicolumn{6}{|l|}{ Residence } \\
\hline Urban & -.0109281 & $.0304979 *$ & $-.0775844 * * *$ & .0131332 & .006396 \\
\hline \multicolumn{6}{|l|}{$\begin{array}{l}\text { Religion (Ref: Tradition- } \\
\text { al/Spiritualist/No religion }\end{array}$} \\
\hline Christian & .0048738 & .0329224 & .0092836 & -.0103739 & -.0052963 \\
\hline Islam & .0161784 & $.0562507 *$ & .0022238 & -.0162111 & .0025328 \\
\hline \multicolumn{6}{|l|}{ Ethnicity(Ref: other) } \\
\hline Akan & .0269507 & $.1454865^{* * *}$ & -.0647428 & .0359911 & .0516615 \\
\hline $\mathrm{Ga} /$ Dangme & .0826768 & $.2033152 * * *$ & -.0575017 & .0553396 & $.0960034 *$ \\
\hline Ewe & .0667151 & $.2089311 * * *$ & $-.0979571^{*}$ & .0449239 & .0651385 \\
\hline Guan & .0616773 & .0906604 & -.053489 & .1017865 & $.1256384 * *$ \\
\hline Mole-Dagbani & $.07546^{*}$ & $.1750327 * * *$ & -.0278927 & .0612048 & $.0843141 *$ \\
\hline Grusi & .074672 & $.137086^{* *}$ & -.0067375 & .0665237 & $.1058927 *$ \\
\hline Gurma & -.0426816 & .0605423 & $-.1128341 * *$ & -.0550015 & -.0535215 \\
\hline Mande & $.1740878 * * *$ & $.2071394 * * *$ & -.0418908 & .047641 & .113462 \\
\hline \multicolumn{6}{|c|}{$\begin{array}{l}\text { Mother's Education (Ref: Unedu- } \\
\text { cated) }\end{array}$} \\
\hline Primary & .0007086 & .0184027 & $.0321172 *$ & .0009508 & -.0191873 \\
\hline Secondary & $.0431675^{* *}$ & $.0578301 * * *$ & $.05701 * * *$ & .028404 & .0194398 \\
\hline Higher & .0365684 & $.0743072 *$ & .064055 & .0250654 & .0059191 \\
\hline \multicolumn{6}{|c|}{$\begin{array}{l}\text { Mother's Insurance(Ref: Unin- } \\
\text { sured) }\end{array}$} \\
\hline Insured & .0065101 & $.0411707 * * *$ & $.0332583^{* *}$ & .0067697 & .0005121 \\
\hline \multicolumn{6}{|c|}{$\begin{array}{l}\text { Marital Status (Ref: Single Moth- } \\
\text { ers) }\end{array}$} \\
\hline Employed & $.0516401 * * *$ & .0230205 & $.034099 * *$ & $.0541613 * * *$ & $.0481056^{* * * *}$ \\
\hline \multicolumn{6}{|c|}{$\begin{array}{l}\text { Permission to Seek Medical Care } \\
\text { by Mother (Ref: Not a big prob- } \\
\text { lem) }\end{array}$} \\
\hline Big Problem & -.013339 & .003491 & -.0165122 & .0017693 & .0212443 \\
\hline \multicolumn{6}{|c|}{ Money to Seek Medical Care by } \\
\hline \multicolumn{6}{|c|}{ Mother (Ref: Not a big problem) } \\
\hline Big Problem & .0052668 & .0208162 & -.0171736 & -.004508 & -.0109479 \\
\hline \multicolumn{6}{|c|}{ Distance to Seek Medical Care by } \\
\hline \multicolumn{6}{|c|}{ Mother (Ref: Not a big problem) } \\
\hline Big Problem & -.0163249 & -.0127886 & .0089444 & .0180564 & $.0273362 *$ \\
\hline \multicolumn{6}{|c|}{$\begin{array}{l}\text { Partner's Education (Ref: Unedu- } \\
\text { cated) }\end{array}$} \\
\hline Primary & .0079032 & .028514 & .0080398 & .0031536 & .028717 \\
\hline Secondary & .0191173 & $.0430786 * *$ & -.0067679 & .0113096 & $.0386271 *$ \\
\hline Higher & .0071381 & $.0639698 * *$ & .0088649 & .024883 & $.0734837 * *$ \\
\hline \multicolumn{6}{|c|}{$\begin{array}{l}\text { Sex of Household head (Ref: Fe- } \\
\text { male Head) }\end{array}$} \\
\hline Male head & .0129475 & .0251423 & -.0070846 & $-.0371018 * *$ & -.0122194 \\
\hline Sex of Child (Ref: Femal & & & & & \\
\hline Male Child & -.0039511 & -.0105276 & -.00013 & -.0020021 & -.0061394 \\
\hline Wealth (Ref: Non-Rich) & & & & & \\
\hline Rich & $-.0348546^{*}$ & .0296453 & $.0413539 *$ & .0133997 & .0010351 \\
\hline Mother's Age & $.0048729 * * *$ & $.0087163 * * *$ & .0013995 & .0010194 & $.0028369 *$ \\
\hline Age of Household Head & $-.0012891 * *$ & $-.001808 * * *$ & -.0001042 & -.0007321 & $-.001878 * * *$ \\
\hline Birth Order of Child & $-.0133703 * * *$ & $-.0246294 * * *$ & -.0071245 & -.0054823 & -.008168 \\
\hline Childs Age & $.0345582 * * *$ & -.0044372 & $.1227777 * * *$ & $-.1249063 * * *$ & $-.1141308 * * *$ \\
\hline & $\mathrm{N}=5126$ & $\mathrm{~N}=5140$ & $\mathrm{~N}=5128$ & $\mathrm{~N}=5066$ & \\
\hline & $\begin{array}{l}\text { Prob }>\text { chi } 2= \\
0.0000\end{array}$ & $\begin{array}{l}\text { Prob }>\text { chi } 2= \\
0.0000\end{array}$ & $\begin{array}{l}\text { Prob }>\text { chi } 2= \\
0.0000\end{array}$ & $\begin{array}{l}\mathrm{N}=5066 \\
\text { Prob }>\text { chi } 2=0.0000\end{array}$ & $\begin{array}{l}\mathrm{N}=5073 \\
\text { Prob }>\text { chi } 2=0.0000\end{array}$ \\
\hline
\end{tabular}

Source: Author's computation from the 2014 GDHS. Notes: 1. ***P-value<.01, **P-value<.05, *P-value<.1. 2. Traditional in this study means traditional/ spiritualist/ no religion.

On the determinants of utilisation of all the doses of the Pentavalent vaccine, the results showed that on average, children from the Western, Northern and Eastern regions were 11\%, 12\% and $8 \%$ respectively less probable to have received all doses of the pentavalent vaccine relative to those in the Upper west region. These send signals on reinvigoration of regional centeredness concerning 
the issue of full utilisation of vaccines for children in Ghana. The result conflicts that of Logullo et al. (2008) who revealed region not to be linked with adequate utilisation of measles vaccine in Sao Paulo City (Brazil) but concurs with that of Matthews and Diamond (1997) who found region to be essential in determining immunization of children in Ghana and the findings of Immurana and Arabi (2016c) on the Western, Northern and Eastern regions with regards to the demand for the $3^{\text {rd }}$ dose of the Pentavalent vaccine for children in Ghana. On ethnicity, the results showed that on the average, children with Mande and Mole-Dagbani ethnic backgrounds were $17 \%$ and $8 \%$ respectively more probable to have been offered all doses of the Pentavalent vaccine relative to those from the other ethnic groups. The result on Mande ethnicity concurs with Immurana and Arabi (2016 c) on the demand for the $3^{\text {rd }}$ dose of the Pentavalent vaccine for children in Ghana but contrary in the case of Mole Dagbani since it was found to be insignificant by Immurana and Arabi (2016c) with regards to demand for the $3^{\text {rd }}$ dose of the Pentavalent vaccine for children in Ghana.

Further, mothers with secondary education were found to be $4 \%$ more likely to have demanded all doses of the Pentavalent vaccine for their children relative to their uneducated counterparts. This is not startling since educated mothers can better appreciate the importance of utilising all doses of vaccines for their children relative to their uneducated counterparts. The finding is similar to that of Ibnouf et al. (2007) in Sudan, Dwumoh et al. (2014) and Matthews and Diamond (1997) in Ghana and that of Immurana and Arabi $\left(2016 \mathrm{c}\right.$ ) on the demand for the $3^{\text {rd }}$ dose of the Pentavalent vaccine for children in Ghana.

Further, employed and married mothers were on the average 5\% and $4 \%$ more probable to demand all the three doses of the Pentavalent vaccine for their children relative to the unemployed and single mothers respectively. The finding on mother's employment is similar to that of Immurana and Arabi (2016 c) on the demand for the $1^{\text {st }}, 2^{\text {nd }}$ and $3^{\text {rd }}$ doses of the Pentavalent vaccine for children in Ghana. Further, the finding on married mothers is similar to that of Immurana and Arabi $\left(2016 \mathrm{c}\right.$ ) on the demand for the $3^{\text {rd }}$ dose of the pentavalent vaccine for children in Ghana. Thus even though these vaccines are administered for free, employed and married mothers could get monetary support from their jobs and husbands respectively and hence would be more capable to cater for any indirect costs of immunisation such as transportation cost. Also married women could be boosted in visiting immunisation centres in order to utilise these vaccines for their children by enjoying company from their husbands. Surprisingly, wealthy households children were $3 \%$ less probable to have been offered all the doses of the Pentavalent vaccine relative to their non-wealthy households counterparts. This is similar to the finding of Immurana and Arabi (2016 c) with regard to the demand for the $3^{\text {rd }}$ dose of the Pentavalent vaccine for children in Ghana.

Also averagely as the ages of the child and mother increased by a year, the likelihood that a child received all doses of the Pentavalent vaccine increased by $3 \%$ and $.5 \%$ respectively. The result on child's age concurs with that of Ibnouf et al. (2007) in Sudan. The result on mother's age could be due to more experience on the part of older mothers than their younger counterparts and therefore would better know how important utilising all the doses of the Pentavalent vaccine is to the survival of children. Also the result on child's age is not startling since subsequent doses of vaccines are offered if only the child has attained a certain age and hence leading to older children being more likely to be offered all the doses of the Pentavalent vaccine as compared to their younger counterparts who may not have attained the required age to be offered all the doses especially the subsequent ones. Conversely, on average as the age of the household head and birth order of the child increased by a year, the likelihood that a child received all doses of the pentavalent vaccine fell by $.1 \%$ and $1 \%$ respectively. The finding on older household heads could be due to the seemingly negative perceptions some older people have about modern medicine. The result on birth order could be that caregivers detected some side effects which might accompany certain vaccines when they utilised for their previous or older children and hence would not be willing to utilise for their subsequent births (high birth ranked children). The results on ages of the mother, child and household head as well as birth order of the child are all similar to the findings of Immurana and Arabi (2016 c) with regards to the demand for the $2^{\text {nd }}$ and $3^{\text {rd }}$ doses of the Pentavalent vaccine for children in Ghana.

On the determinants of utilising of all the four doses of the Polio vaccine, children from the Western, Greater Accra, Central, Volta, Eastern, Brong Ahafo, Ashanti and Northern Regions were respectively on average $16 \%, 7 \%, 13 \%, 15 \%, 22 \%, 11 \%, 15 \%$ and $21 \%$ less probable to have been offered all the doses of the polio vaccine relative to those in the Upper West region. The results on the less likelihood of utilising all doses of the polio vaccine for children from the Western, Northern and Eastern regions are similar to those revealed under the utilisation of all the three doses of the pentavalent vaccine for children.

Also children from Islamic background and urban areas were $6 \%$ and 3\% more likely to have received all the four doses of the Polio vaccine as compared to those from traditional/spiritualist/no religion background and rural areas respectively. The finding on urban children is similar and contrary to that of Immurana and Arabi (2016c) in the case of demand for the $1^{\text {st }}$ dose (Polio 0) and $2^{\text {nd }}$ dose (Polio1) of the Polio vaccine for children in Ghana respectively.

On ethnicity, averagely, children from Ga/Dangme, Akan, Ewe, Grusi, Mole-Dagbani, and Mande ethnicities were 20\%, 15\%, $21 \%, 14 \%, 18 \%$, and $21 \%$ respectively more likely to have been offered all the doses of the Polio vaccine relative to their counterparts from the other ethnic groups.

In addition on average, mothers with higher and secondary education, married mothers and mothers who had health insurance were $7 \%, 6 \%, 4 \%$ and $4 \%$ respectively more probable to have demanded all the four doses of the polio vaccine for their children as compared to the uneducated mothers, single mothers and mothers without health insurance respectively. The finding on marital status contradicts that of Logullo et al. (2008) who revealed marital status not to be linked with adequate utilisation of measles vaccine in Sao Paulo City (Brazil) but similar to that of Immurana and Arabi $(2016 \mathrm{c})$ in the case of demand for the $1^{\text {st }}$ dose (Polio 0) and $4^{\text {th }}$ dose (Polio3) of the polio vaccine for children in Ghana respectively.

Moreover, the result on health insurance which is similar to that of Immurana and Arabi (2016c) in the case of demand for the $1^{\text {st }}$ dose (Polio 0) of the polio vaccine for children in Ghana was expected. This is because health insurance gives easy access to health centres and other health facilities where immunization drives as well as education on the essence of fully utilising vaccines is to child survival are normally embarked upon and hence, making mothers with health insurance more likely to demand all the doses of the polio vaccine for their children as compared to their counterparts without health insurance.

Also, children whose mothers had partners with higher and secondary levels of education were $6 \%$ and $4 \%$ respectively more probable to have received all the four doses of the Polio vaccine relative to their counterparts whose mothers had uneducated partners. These are similar to that of Immurana and Arabi (2016c) in the case of demand for the $1^{\text {st }}$ dose (Polio 0) of the polio vaccine for children in Ghana. The findings are not surprising since the educated can better comprehend the essence of vaccines to child survival than the uneducated.

Also on average, a yearly increase in mother's age was found to increase the probability that a child was offered all the doses of the polio vaccine by. $9 \%$. On the contrary, on average as the age of the household head and birth of order of the child increased, the likelihood that a child received all doses of the Polio vaccine fell by $.2 \%$ and $2 \%$ respectively.

On the utilisation of both doses of the Measles vaccine for children in Ghana, on average, children from the Volta, Western, Eastern, Upper East and Brong Ahafo regions were respectively 
$11 \%, 6 \%, 12 \%, 6 \%$ and $9 \%$ more probable to have been offered all doses of the Measles vaccine relative to children in the Upper West region. The findings on Volta, Eastern, Upper East and Ashanti regions conflict with those of Immurana and Arabi (2016b) who found these regions to be insignificant in the case of demand for the $1^{\text {st }}$ dose of the Measles vaccine for children in Ghana. However, the findings on Volta, Eastern and Brong Ahafo regions are similar to that of Immurana and Arabi (2016b) in the case of demand for the $2^{\text {nd }}$ dose of the Measles vaccine for children in Ghana.

Concerning residence, urban children were $8 \%$ less likely to have received both doses of the Measles vaccine relative to rural children which is similar to that of Immurana and Arabi (2016b) in the case of demand for the $1^{\text {st }}$ and $2^{\text {nd }}$ doses of the Measles vaccine for children in Ghana. This can be attributed to probably the over concentration on rural areas to the neglect of urban areas in child health utilisation drives given that rural areas are normally seen to be more vulnerable. With regards to ethnicity, on average, children from Gurma and Ewe households were 11\% and $10 \%$ respectively less likely to have been offered both doses of the Measles vaccine relative to those from the other ethnic groups. The results on ethnicity concur with those of Immurana and Arabi (2016b) in the case of demand for the $2^{\text {nd }}$ dose of the Measles vaccine but contrary in the case of demand for the $1^{\text {st }}$ dose of the Measles vaccine for children from the Ewe ethnicity in Ghana who were found to be more likely to have received by Immurana and Arabi (2016b).

On maternal education, mothers with secondary and primary levels of education were on the average $6 \%$ and $3 \%$ more likely to demand both doses of the measles vaccine for their children as compared to the uneducated mothers. This is in line with the findings of Cockcroft et al. (2014) and Cockcroft et al. (2009) who found mother's education to influence the probability that a child received the measles vaccine in Nigeria and Pakistan respectively. Also employed and insured mothers were both $3 \%$ more likely to demand both doses of the measles vaccine for their children as compared with the unemployed and uninsured mothers respectively. The findings on mothers health insurance conflicts with those of Immurana and Arabi (2016b) in the case of demand for the $1^{\text {st }}$ dose of the measles vaccine because it was insignificant but similar in the case of demand for the $2^{\text {nd }}$ dose of the measles vaccine. Also the result on mother's employment is similar to that of Immurana and Arabi (2016b) in the case of demand for the $1^{\text {st }}$ dose and $2^{\text {nd }}$ dose of the measles vaccine.

Moreover, wealthy households' children were $4 \%$ more probable to have been offered both doses of the measles vaccine relative to non-wealthy households' children. This concurs with the findings of Cockcroft et al. (2009) in Pakistan and that of Immurana and Arabi (2016b) in the case of demand for the $2^{\text {nd }}$ dose of the measles vaccine for children in Ghana.

On average, a yearly increase in a child's age was found to increase the probability of demanding both doses of the measles vaccine by $12 \%$. This is in line with the findings of Otieno et al. (2014) who revealed older children to be probable to have received influenza vaccination in Kenya and that of Immurana and Arabi (2016b) in the case of demand for the $1^{\text {st }}$ dose and $2^{\text {nd }}$ dose of the measles vaccine for children in Ghana.

On the utilisation of both doses of the rotavirus vaccine, on average, mothers from the Volta, Greater Accra, Eastern, Upper East and Brong Ahafo regions were respectively $10 \%, 20 \%, 11 \%, 11 \%$ and $26 \%$ more likely to have utilised both doses of the rotavirus vaccine for their children relative to their counterparts in the Upper West region. Also on average, employed mothers were found to be 5\% more likely to demand both doses of the rotavirus vaccine for their children as compared with the unemployed mothers. In addition, children with male household heads were on average $4 \%$ less likely to have been offered both doses of the rotavirus vaccine relative to children with female household heads. The results on region, mother's employment and male household heads are similar to the findings of Immurana and Arabi (2016a) on the utilisation of the 1 st dose and $2^{\text {nd }}$ dose of the rotavirus vaccines for children in Ghana.

Further, on average, a yearly increase in a child's age decreased the probability of demanding both doses of the rotavirus vaccine by $12 \%$. The finding on child's age could be that older children were too old to be offered all doses of the rotavirus vaccine at the recommended ages $\left(6\right.$ weeks for the $1^{\text {st }}$ dose and 14 weeks for the $2^{\text {nd }}$ dose) since the vaccine was introduced in 2012 and the study used data on children born five years preceding the survey year/month of 2014 /September. This result is similar to that of Immurana and Arabi (2016a) with regard to the utilisation of the 1 st dose and $2^{\text {nd }}$ dose of the rotavirus vaccines for children in Ghana.

Moreover, results on the utilisation of all the three doses of the pneumococcal vaccine showed that on average, children from the Volta, Greater Accra, Eastern, Upper East and Brong Ahafo regions were respectively $10 \%, 17 \%, 11 \%, 9 \%$ and $25 \%$ more likely to have received all doses of the pneumococcal vaccine relative to those in the Upper West region. The results on region are similar to the findings of Immurana and Arabi (2016a) on the utilisation of the 1 st dose, $2^{\text {nd }}$ dose and $3^{\text {rd }}$ dose of the pneumococcal vaccine for children in Ghana. On ethnicity, on average, children with Guan, Ga/Dangme, Grusi and Mole-Dagbani backgrounds were $13 \%, 10 \%, 11 \%$ and $8 \%$ respectively more probable to have been offered all doses of the pneumococcal vaccine relative to children from the other ethnic groups. These concur with the findings of Immurana and Arabi (2016a) on the utilisation of the $2^{\text {nd }}$ dose and $3^{\text {rd }}$ dose of the pneumococcal vaccine for children in Ghana.

Further, employed and married mothers were 5\% and $4 \%$ more likely to demand all the doses of the pneumococcal vaccine for their children relative to unemployed and single mothers respectively. These findings are similar to the findings of Immurana and Arabi (2016a) on the utilisation of the 1 st dose, $2^{\text {nd }}$ dose and $3^{\text {rd }}$ dose of the pneumococcal vaccine for children with employed mothers and on the utilisation of the $2^{\text {nd }}$ dose and $3^{\text {rd }}$ dose of the pneumococcal vaccine for children with married mothers in Ghana.

Further, mother's with big problems concerning distance in seeking medical care for themselves were found to be $3 \%$ more likely to demand all doses of the pneumococcal vaccine for their children as compared to mothers who did not see distance as a big problem in seeking medical help. This contradicts the findings of Immurana and Arabi (2016a) who found distance not to be a significant determinant on the utilisation of the 1 st dose, $2^{\text {nd }}$ dose and $3^{\text {rd }}$ dose of the pneumococcal vaccine for children. The reason could be that since mothers have challenges with regards to seeking care, they resort to more preventive measures for themselves and their children.

In line with the expectation of the study, children whose mothers had Partners with Higher and Secondary education were $7 \%$ and $4 \%$ respectively more probable to have received all the three doses of the pneumococcal vaccine relative to children whose mothers had uneducated partners which are in line with the results of Immurana and Arabi (2016a) on the utilisation of the $3^{\text {rd }}$ dose of the Pneumococcal vaccine for children in Ghana. Also on average, a yearly increase in mother's age was found to increase the probability of children receiving all doses of the Pneumococcal vaccine by .3\%. This concurs with that of Immurana and Arabi (2016a) on the utilisation of the $3^{\text {rd }}$ dose of the Pneumococcal vaccine for children in Ghana

Last but not the least, averagely, as the ages of the child and that of the household head increased by a year, the probability that children received all doses of the pneumococcal vaccine fell by $11 \%$ and $.2 \%$ respectively. Similar results were obtained by Immurana and Arabi (2016a) on the utilisation of the $3^{\text {rd }}$ dose of the pneumococcal vaccine for children in Ghana. The finding on child's age could be that older children were too old to be offered all doses of the pneumococcal vaccine at the recommended ages 
( 6 weeks for the $1^{\text {st }}$ dose, 10 weeks for the $2^{\text {nd }}$ dose and 14 weeks for the 3rd dose) since the vaccine was introduced in 2012 and the study used data on children born five years preceding the survey year/month of 2014 /September. The findings are further similar to that of Immurana and Arabi (2016a) with regard to the utilisation of the 1 st dose and $2^{\text {nd }}$ dose of the rotavirus vaccines for children in Ghana.

\section{Conclusion}

From the findings, the study can conclude that residence, region, ethnicity, mother's health insurance, education, mother's employment, partner's education, religion, household wealth, birth order, marital status of mother, child's age, distance to seek medical care by mother and sex of household head are significant factors when it comes to determining the utilisation of all doses of vaccines. It must however be stressed that, it does not necessarily mean all these factors individually had significant effects on the utilisation of all doses of the individual vaccines the study considered. Therefore from the findings, the study would recommend the following:

1) Reinvigoration of the regional child health utilization drives should be highly prioritized. This is because children from the Eastern, Northern and Western regions were found to be less probable to have utilized all the doses of the polio and pentavalent vaccines whiles children in all the remaining other regions except the Upper East region, were also revealed to be less probable to have been offered all the doses of the polio vaccine.

2) Affirmative action and initiatives that would enhance job opportunities for women should be encouraged since employed mothers were more likely to demand for all the doses of the measles, pentavalent, pneumococcal and rotavirus vaccines for their children as compared to their unemployed counterparts. As a short term strategy, unemployed women can be aided with regards to the immunization of their children.

3) Educating mothers and household heads through the media and any other means available in order for them to understand the need for all children irrespective of their birth order or nature to be immunized should be embarked upon. This is because rising birth order was revealed to be associated with the less likelihood that children received all doses of the pentavalent and polio vaccines. Also children with male household heads were less likely to receive all the doses of the rotavirus vaccine and rising age of the household head was associated with falling utilization of all the doses of the pneumococcal, pentavalent and polio vaccines for children.

4) Special attention should also be given to vulnerable women such as less educated or uneducated mothers and single mothers with regards to the health utilization of their children. This is because children with single mothers were found to be less likely to have received all doses of both the polio and pentavalent vaccines. Also uneducated mothers were found to be less likely to demand for all the doses of the polio, pentavalent and measles vaccines for their children relative to mothers with secondary education. Moreover, enhancing girl child education could be an effective long term strategy.

5) Also further strengthening the free maternal health insurance registration under the National health insurance scheme should be encouraged given that insured mothers were more likely to utilize all the doses of the measles and polio vaccines for their children relative to the uninsured mothers.

6) Also in our attempt to help vulnerable rural dwellers, care must be taken not to ignore urban dwellers with regard to child health utilization drives since urban children were less likely to have received both doses of the measles vaccine.

7) Helping younger mothers could be relevant since rising maternal age was found to be linked with the utilization of all doses of the polio, pentavalent and pneumococcal vaccines for children in Ghana.

\section{Acknowledgement}

We are thankful to the DHS Program for the data

\section{Conflicts of interest}

None declared

\section{References}

[1] Bosu KW, Ahelegbe D, Edum-Fotwe E, Bainson AK \& Turkson KP (1997) Factors influencing attendance to immunization sessions for children in a rural district of Ghana. Acta Tropica 68, 259-267, Elsevier. http://dx.doi.org/10.1016/S0001-706X (97) 00094-6.

[2] Cockcroft A, Usman UM, Nyamucherera FO, Emory H, Duke B, Umar AN \& Andersson N (2014) Why children are not vaccinated against measles: a cross-sectional study in two Nigerian States. Archives of Public Health, 72(48). Retrieved from http://www.archpublichealth.com/content/72/1/48. https://doi.org/10.1186/2049-3258-72-48.

[3] Duah-Owusu M (n.d.) Social Determinants and Immunisation in Ghana: Is there an Association? Unpublished MPhil Thesis, University of Bergen research centre for health promotion and development, faculty of psychology.

[4] Dwumoh D, Essuman EE \& Afagbedzi KS (2014) Determinant of factors associated with child health outcomes and service utilization in Ghana: multiple indicator cluster survey conducted in 2011. Archives of Public Health, 72(42). Retrieved from http://www.archpublichealth.com/content/72/1/42. https://doi.org/10.1186/2049-3258-72-42.

[5] Ghana Health Service (2015) Ghana Health Service 2014 Annual Report.

[6] Ghana Health Service (n.d.) 2014 Family Health Annual Report.

[7] Ghana Statistical Service (GSS), Ghana Health Service (GHS) \& ICF International. (2015). Ghana Demographic and Health Survey 2014. Rockville, Maryland, USA: GSS, GHS, and ICF International

[8] Grossman M (1999) the Human Capital Model and the Demand for Health. NBER Working Paper No. 7078. https://doi.org/10.3386/w7078.

[9] Immurana M \& Arabi U (2016a) Determinants of demand for subsequent doses of pneumococcal and rotavirus vaccines for children less than five years of age in Ghana, International Journal of Health 4 (2), 120-127. doi: 10.14419/ijh.v4i2.6114

[10] Immurana M \& Arabi U (2016b) Demand for measles and yellow fever vaccines for children in Ghana: are socio-economic, demographic and Geographic factors relevant?, International Journal of Accounting and Economics Studies, 4 (2),136-141. https://doi.org/10.14419/ijaes.v4i2.6526.

[11] Immurana, M \& Arabi U (2016c) Socio-economic determinants of successive polio and pentavalent vaccines utilisation among underfive children in Ghana (Unpublished Manuscript).

[12] Lakew Y, Bekele A, \& Biadgilign S (2015) Factors influencing full immunization coverage among 12-23 months of age children in Ethiopia: evidence from the national demographic and health survey in 2011. BMC Public Health, 15(728). https://doi.org/10.1186/s12889-015-2078-6.

[13] Loving S (2016) Vaccine Knowledge Project, Authoritative Information for All. Oxford Vaccine group, University of Oxford. 2016. Accessed from: www.ovg.ox.ac.uk/pertusis-whooping-cough on 4th April, 2016

[14] Matthews Z \& Diamond I (1997) Child Immunisation in Ghana: The Effects of Family, Location and Social Disparity, Journal of Biosocial Science, 29(03), 327 - 343. DOI: null, Published online: 04 April 2001.

[15] McGlynn KN (2012) Antenatal Care as a Determinant of Immunization, and Appropriate Care for Fever and Diarrhoea in Ghanaian Children. Unpublished MSc Thesis in Epidemiology \& Biostatistics, 
the School of Graduate and Postdoctoral Studies, the University of Western Ontario, London, Ontario, Canada.

[16] Otieno AN, Nyawanda OB, Audi A, Emukule G, Lebo E, Bigogo G, Ochola R, Muthoka P, Widdowson M-A, Shay KD, Burton CD, Breiman FR, Katz AM \& Mott AJ (2014) Demographic, socioeconomic and geographic determinants of seasonal influenza vaccine uptake in rural western Kenya, 2011. Vaccine 32, 6699-6704. Retrieved from https://doi.org/10.1016/j.vaccine.2013.10.089.

[17] Russo G, Miglietta A, Pezzotti P, Biguioh MR, Mayaka BG, Sobze SM, Stefanelli P, Vullo V \& Rezza G (2015) Vaccine coverage and determinants of incomplete vaccination in children aged 12 23months in Dschang, West Region, Cameroon: a cross-sectional survey during a polio outbreak. BMC Public Health, 15(630). https://doi.org/10.1186/s12889-015-2000-2.

[18] World Health Organization (2016a). "Children: Reducing Mortality." Fact Sheet updated September, 2016. Accessed from: http://www.who.int/mediacentre/factsheets/fs178/en/ on 22/05/2017.

[19] World Health Organisation (2016b). Measles: Fact Sheet reviewed March, 2016. Accessed from: http://www.who.int/mediacentre/factsheets/fs286/en/ on 02/06/2016

[20] World Health Organization (2014). Poliomyelitis, Fact Sheet NO 114. 2014 